\title{
A injunção social da maternagem e a violência
}

\author{
Maria Cristina Baluta ${ }^{1}$ \\ Dircéia Moreira $^{1}$ \\ 0000-0002-7666-6066 \\ 0000-0001-6203-0246 \\ 'Universidade Estadual de Ponta Grossa, Ponta Grossa, PR, Brasil. 84010-330 - \\ mestresociaisaplic@uepg.br
}

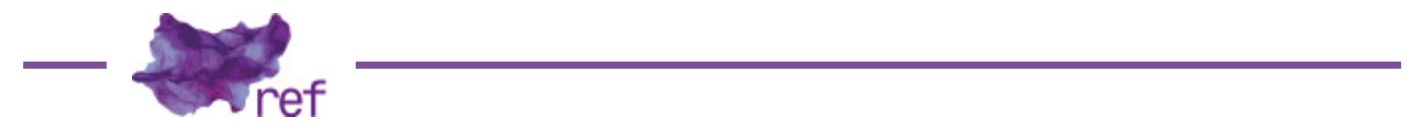

\begin{abstract}
Resumo: Nos últimos séculos a mulher experimentou diversas conquistas relacionadas à sua forma de ser e estar no mundo, se adaptando às conjunturas sociais, econômicas, intelectuais e políticas. Com essa ocupação espacial da mulher, a liberdade de agir e de se expressar ficou mais latente, desobrigando-a dos comportamentos sociais compulsórios. Entretanto, persistem as amarras com alguns padrões seculares, entre eles, o mito da maternagem, que há muito se vincula ao instinto natural de ser mãe. Na contramão dessa imposição social, o Mapa da Violência 2015: Homicídio de Mulheres no Brasil aponta que as crianças, vítimas de violência, também têm as próprias mães como algozes e que as filhas são as mais agredidas. Cuidar de quem cuida é a possibilidade salutar de intervenção nos lares onde a maternagem é situação e não vocação. Para a elaboração do artigo foi utilizado o método da investigação histórica-crítica-propositiva, amparado na pesquisa bibliográfica.

Palavras-chave: mulher; mãe; maternagem; violência; prevenção
\end{abstract}

The Social Injunction of Maternity and Violence

Abstract: In recent centuries the woman has experienced several achievements related to her way of being and being in the world, adapting to social, economic, intellectual and political conjunctures. With this spatial occupation of women, the freedom to act and express themselves became more latent, freeing them from compulsory social behaviors. However, the ties remain with some secular patterns, among them, the myth of mothering, which has long been linked to the natural instinct to be a mother. Contrary to this social imposition, the Map of Violence 2015: Homicide of Women in Brazil indicates that children, victims of violence, also have their own mothers as executioners and that the daughters are the most attacked ones. Caring for the caregiver is the salutary possibility of intervention in homes where the mothering is situation and not vocation. For the elaboration of the article the method of historicalcritical-propositive investigation was used, supported in the bibliographical research.

Keywords: woman; mother; maternity; violence; prevention

\section{Introdução}

Quando se pensa a imagem feminina na atualidade se dispara um misto de interpretações ancestrais coexistentes com a postura da mulher do século XXI. Apesar de a mulher estar presente na maioria dos meios de atividades existentes, seu conceito como figura doméstica e responsável pela prole continua arraigado à sua própria essência. Muitas conseguiram abdicar dessa vinculação, mas não sem sofrerem apontamentos sociais de repreensão por não cumprirem seu papel dentro da normalidade imposta pelo sistema comportamental talhado à sua personagem existencial. As opções diversas das culturalmente tributadas à mulher ainda são condicionadas à sua moralidade e desobediência aos ditames transcendentais, vitalizando a sobrevida da 'mística feminina' (Betty FRIEDAN, 1971).

O caminho percorrido pela emancipação feminina, muitas vezes equivocadamente entendida como busca pela igualdade masculina, retrata uma situação de perdas e ganhos, 
pois, independente das motivações, sempre que elege um destino diverso ao compulsoriamente ofertado, a mulher parece estar em débito com a família e a sociedade. Mesmo em sendo, na atualidade, a entidade familiar constituída não necessariamente por vínculos biológicos, se cobra da mulher uma representação insubstituível na formação familiar, ressalvadas algumas exceções (Adalberto FARIA, 2012).

É certo que as noções de feminilidade e masculinidade mudaram ao longo da história conforme as transformações sociais ocorridas, e que o auxílio do companheiro e/ou pai também sofreu alterações fundamentais na divisão das responsabilidades domésticas e parentais. 0 processo de inclusão coadjuvante do homem na vida privada, permeado pelo afeto e companheirismo, está num crescente às exigências de igualdade, concomitante com a assunção da nova experiência paternal.

Com efeito, muitos homens estão simplesmente a reconstruir-se como "provedores modificados"
no contexto de conjugalidades relativamente institucionalistas e genderificadas, em que o
casal e, acima de tudo, entendido e vivido como relação de gênero, muito embora essa
relação dificilmente se encaixe no modelo de ganha-pão masculino ou de uma família
desprovida de afectos. Do ponto de vista das orientações normativas falamos, sem dúvida, de
um modelo de casal aliança, centrado na produção material da vida, mas já modificado pela
maior democratização das relações no interior da família e pelo apelo de uma matriz de família
unida e fusional (Sofia ABOIM, 2010, p. 166).

Entretanto, no Brasil, a questão de gênero permanece como problemática da maioria dos lares, onde a partilha das obrigações ditas 'femininas' está distribuída de forma bastante desigual (Dalka C. A. FERRARI; Tereza C. C. VECINA, 2002). Mesmo com o compartilhamento do orçamento das despesas do lar, ainda é a mulher a principal responsável pela administração das atividades da casa e dos cuidados com a alimentação, higiene, saúde, educação e vida social dos filhos; além da exigência de permanecer atraente aos olhos do companheiro. Esse quadro fica mais agravado nas famílias expostas à vulnerabilidade política-econômica-social tanto no sentido das fragilidades internas quanto externas (Liliana SOUSA et al., 2007, p. 18).

Não se pode esquecer que centenas de milhares de mulheres já conquistaram seu novo papel na sociedade civil, pelo reconhecimento de seus méritos e pela ciência de pertencimento também às dimensões públicas. Não obstante muito ainda deva ser feito em busca da igualdade de condições, a exemplo do mercado de trabalho e sua respectiva remuneração (Olga Maria Boschi Aguiar de OLIVEIRA, 2016)

Nestas condições, a independente mulher do século XXI continua mantendo o 'pé' na família burguesa do século XIX, pois não se libertou e nem se conscientizou plenamente do seu papel de coadjuvante na mantença da casa e dos filhos. Continua se considerando e repassando às gerações a posição de única responsável pela normalidade da sobrevivência familiar, além da tutela constante de suas vidas vinculadas a uma figura masculina, fruto da ainda recente herança patriarcal (José Roberto Tozoni REIS, 2012).

O acúmulo de obrigações e cobranças, somado aos encargos recebidos pela herança social, é capaz de suplantar o amor incondicional e fragilizar a figura da mãe a tal ponto que ela pode transmudar do amor ao ódio inesperadamente. "Embora a violência familiar socialmente sancionada seja de natureza relativamente confinada, ela pode facilmente propagar-se em formas mais severas de agressão" (Anthony GIDDENS, 2005, p. 167).

O objetivo do presente artigo é trazer ao debate a postura adotada pela mulher-matriz, esquecida no aconchego do seu lar, a vivenciar a maternagem sem nenhuma prévia habilitação, cuja consequência pode reforçar os indicadores da violência pueril.

\section{O maniqueísmo da maternidade}

A mulher vem transformando sua maneira de ser e estar no mundo, conquistando gradativamente sua independência financeira, intelectual, profissional e afetiva. No entanto, não consegue romper com a rígida divisão dos papéis sexuais e com o elo da maternidade perfeita como momento de sublimação espiritual no alinhamento grupal (Erving GOFFMAN, 2004).

A multiplicidade de papéis da mulher contemporânea tem robustecido o fenômeno da maternidade tardia, a qual, mesmo implicando maiores riscos de adversidades na gestação, não afasta o anseio pela maternidade, resultado do ainda presente papel preestabelecido à mulher, desde criança, como mãe e cuidadora. "A maternidade continua sendo um projeto de vida das mulheres, independentemente do momento histórico vivenciado" (Manuela Nunes LOPES et al., 2014, p. 926).

A romantização da maternidade como produção de sentido persiste nos discursos das mais variadas áreas e veículos de comunicação, considerando que, além da condição biológica exclusiva da mulher, a maternidade também retrata uma condição social. Na perspectiva das representações do feminino na mídia nacional observa-se que a mulher se mantém naturalizada na condição de mãe. 
Nos textos prevalecem abordagens segundo as quais a mulher, embora sendo retratada de forma diferente (independente, inserida na política ou consumidora de serviços que oferecem novas tecnologias de reprodução), ainda é naturalizada na condição de mãe, por meio de ideias como sua maior responsabilidade em cuidar dos filhos ou uma suposta habilidade inata para o exercício da maternagem (Renata TOMAZ, 2015, p. 160).

Há muito se registra a grandiosidade do amor materno, sendo popularmente inconcebível qualquer conotação negativa ao sentimento existente na relação mãe e filho. De mesma sorte ao conceito de família, a qual se denota como uma unidade harmônica, estruturada no amor perene e na proteção dos seus integrantes. Todavia, a realidade concreta pode se apresentar como um campo dos mais variados conflitos, opressão, individualidade egoística, desamor e violência. Os complexos familiares (Jacques LACAN, 1997) que teriam a função de proteção dos seus membros talvez nunca tenham faticamente cumprido esta missão, pois "outrora, usando meios disciplinares violentos, hoje meios menos coercitivos, mas também entremeados com violência, ela nos mostra que sua face não é sagrada, mas extremamente cruel" (Viviane Nogueira de Azevedo GUERRA, 2001, p. 96).

Pelas influências religiosas e pela dominação masculina, o papel da mulher como mãe é sacralizado e, quando da gestação, como num passe de mágica passa a ter uma auréola sobre sua cabeça, exigindo um olhar diferenciado e, em especial, passando a ser compreendida como provedora da paz e da união familiar. Jean Jacques Rousseau, ao escrever a obra Emílio ou da Educação, no século XVIII, idealizou a figura materna em uma analogia com a freira, afirmando que "a boa mãe é semelhante à boa religiosa ou se esforçará para sê-lo. Mais um passo, e terá direito ao título de 'santa'" (Elizabeth BADINTER, 1985, p. 245). Essa correspondência ainda é bastante perceptível na hodiernidade.

O endeusamento da figura materna reflete na imposição de toda mulher ser uma boa mãe, desprezando-se todo contexto de sua vida até então; desconsiderando o seu temperamento, a sua moral constituída e constituinte, valores e caráter. Coisifica-se a sua individualidade e infligeIhe socialmente um comportamento padronizado, reflexo da sua condição natural de mãe: exemplo de amor e abnegação em prol dos filhos, independente das relações sociais de classe (FARIA, 2012).

Passado o 'estado de graça' da gestação, a verdade feminina volta a ser a das cobranças infindáveis sobre seu comportamento familiar, uma vez que todas as suas obrigações retornam ao seu comando e responsabilidade, acrescidas da indispensabilidade de sua atuação primordial como cuidadora e educadora da prole.

Com a maternidade, a aparência corporal da mulher resultará modificada e não raras vezes será rechaçada por não ser o que era antes e por não estar disponível nos momentos de intimidade. Será questionada ao não conseguir manter a mesma organização do trabalho doméstico e por não contribuir satisfatoriamente com as despesas do lar como outrora. As possibilidades da existência de depressão e baixa autoestima, permeadas pela insegurança, passam a existir concomitantemente com as fantasias femininas em um retorno lúdico de amar e ser amada (Julia KRISTEVA, 1989).

No ambiente profissional, superada a fase da idolatria maternal, a realidade feminina é bem diferente, pois a gravidez, ou a sua possibilidade, é fator predominante para considerar sua força de trabalho como secundária, levando em conta o risco permanente de afastamento e licenças na rotina laboral. Esse comportamento é tão visível e previsível que o número de filhos de mulheres trabalhadoras vem reduzindo significativamente nos últimos tempos (FARIA, 2012).

Sem dúvida a evolução social da mulher é desmesurada em inúmeros aspectos, mas em relação à maternidade continua a ser um tema sacro-inviolável, defendido inclusive pela maioria das mulheres que se nega ousar pensar diferente da maternagem como instinto. Há um sentimento de culpa tão intenso, que se presente a insatisfação pessoal de seu papel social materno, que preferem manter o pacto do silêncio, suportando o acúmulo de atribuições e cobranças interiorizadas, mesmo representando um risco iminente de uma sobrecarga explosiva.

O rótulo imposto à mulher que não cumpre o papel de boa mãe pulsa latente em sua vida, desconsiderando o seu habitat de conflitos, ausências e privações. A ela foi delegada uma etiqueta sem a qual sua identidade social é prejudicada (GOFFMAN, 2004).

Nestas condições, quando os desejos subjetivos da individualidade feminina vão de encontro à construção social da maternidade, inevitavelmente resultarão em perdas significativas: a uma pela prática do aborto ou abandono, a duas, pela prática da violência intrafamiliar.

\section{A fabricação do amor materno}

A concepção de amor materno que experimentamos atualmente é bastante recente. Nos relatos históricos é destacada a invisibilidade da criança nas relações interpessoais, passando pela recusa de sua amamentação até a completa negligência, reputando-a inclusive como um estorvo. A falta de afeição pelas crianças na família medieval é retratada em inúmeros fragmentos 
relacionados à vida privada no Ocidente, cujas crianças (pequenos adultos) permaneciam nas casas com sua família até completarem a idade de sete anos; oportunidade em que eram encaminhadas a outras casas (trocas de crianças para melhor servirem os adultos), num misto de aprendiz, pensionista ou criado. Ao retornarem, os meninos eram encaminhados aos seus preceptores e as meninas ficavam ao encargo das governantas. Somente a partir do século XV é que a educação passou a ser fornecida pela escola para a camada média da hierarquia social e a haver um convívio maior entre os pais e filhos; ressalvada a situação das meninas, as quais só conseguiram acesso nas escolas ao final do século XVIII (Philippe ARIÈS, 1981).

Os tratados de civilidade difundidos a partir do século XVII, propostos inicialmente com a finalidade de registrar os hábitos dos adultos para as crianças ou outros adultos ineptos, transmudaram para a instrução "da própria família sobre seus deveres e suas responsabilidades, e de aconselhá-la em sua conduta com relação às crianças" (ARIÈS, 1981, p. 255).

Para o sociólogo francês Jacques DONZELOT (1980), a crescente mortalidade infantojuvenil capaz de causar redução demográfica e de consequência prejuízo futuro na produção (mão de obra) e na defesa (propriedade), somada à dificuldade de acesso e condição de remuneração das nutrizes (amas de leite), foi propulsora de uma estratégia estatal. Essa evidência faz surgir, a partir da metade do século XVIII, uma vasta literatura discutindo sobre a conservação das crianças e os costumes da época, enfatizando, entre outras coisas, que as crianças que demonstravam mau comportamento tinham herdado a índole de suas nutrizes, e que se suas mães tivessem as alimentado, certamente teriam sido honestas. A propositada mensagem de culpabilizar as mães era direta: os maus hábitos e vícios podem ser transmitidos na amamentação.

Ao final do século XVIII, os médicos tiveram grande influência nas famílias burguesas, por meio de livros sobre a criação, educação e medicação das crianças, delegando à mãe o papel de cuidadora. Essa postura foi direcionada a três pontos em específico: a evitação da influência dos métodos e preconceitos serviçais, a promoção da mulher pelo reconhecimento de sua utilidade educativa (valoração feminina) e o fortalecimento da família (sinônimo de felicidade) em face da forma de educação, da disciplina religiosa e do hábito do internato. A assunção das responsabilidades pelos filhos passa a ser a principal fonte de afeto e proteção, naturalizando, por meio do discurso higienista, o mito do amor materno. A família passa de instituição a mecanismo, fazendo parte da construção social o papel da mulher como mãe dedicada, abençoada e idolatrada (DONZELOT, 1980).

Quando a pioneira Elisabeth Badinter publicou os resultados de uma extensa pesquisa sobre o mito do amor materno, concluindo que esse amor pode ser incerto, frágil e imperfeito, provocou um enorme mal-estar entre homens e mulheres, recebendo acirradas críticas de representantes de diversas áreas de conhecimento, com a alegação de assincronismo e de configurar uma afronta ao amor mais sublime e natural de que se tem experiência. No consciente coletivo o amor materno é concebido em termos de instinto:

[...] acreditamos facilmente que tal comportamento seja parte da natureza da mulher, seja qual for o tempo ou o meio que a cercam. Aos nossos olhos, toda mulher, ao se tornar mãe, encontra sem si mesma todas as respostas à sua nova condição. Como se uma atividade préformada, automática e necessária esperasse apenas a ocasião de se exercer. Sendo a procriação natural, imaginamos que ao fenômeno biológico e fisiológico da gravidez deve corresponder determinada atitude maternal (BADINTER, 1985, p. 20).

Ainda, segundo a filósofa francesa, sedimentado em fatos históricos, o amor materno deve ser conquistado, pois não é inato e sim circunstancial, onde seu grau de existência está vinculado às condições internas e externas experimentadas pela mulher. Esse mito foi incutido na própria representação da mulher e no seu status social, passando a fazer parte da sua própria natureza (BADINTER, 1985).

Há sem dúvida um número incontável de mulheres que se realiza na maternidade e consegue superar as mais distintas crises, conflitos pessoais e relacionais, comprovando que 0 amor materno existe; porém, não se pode insistir no entendimento de que todas as mulheres, quando mães, amam seus filhos de forma incondicional e igualitária.

Não obstante, o discernimento e falsa aceitação da opção das mulheres poderem decidir sobre a maternidade; a repetição da beatitude do papel social de ser mãe e da precípua responsabilidade pelos filhos continua a ser incentivada, induzida e condicionada às novas gerações, de forma explícita ou subliminar, pelas vias religiosas, culturais e do consumo.

\section{A violência materna}

A violência é um problema social que sempre fez parte da história da humanidade; mas somente em 2002, apesar do sentido polissêmico, a violência teve uma definição mais incisiva por meio da Organização Mundial da Saúde, a qual a considerou como a utilização da "força ou poder em uma forma de ameaça ou efetivamente, contra si mesmo, outra pessoa ou grupo ou comunidade, que ocasiona ou tem grandes probabilidades de ocasionar lesão, morte, dano 
psíquico, alterações do desenvolvimento ou privações" (Maria Cecília de Souza MINAYO, 2005). Por ser um tema complexo e consequência de várias causas, vinculado à determinada época, local e cultura, sua definição não é unissonante (MINAYO, 2005).

No Brasil, a diversificação territorial impossibilita um trabalho estatístico exato da real situação de violência intrafamiliar em cada localidade. Utilizando-se do mais recente Mapa da Violência de 2015: Homicídio de Mulheres no Brasil (Julio Jacobo WAISELFISZ, 2015), que aponta um número alarmante de atendimentos femininos, pode ser observado o número de registros das vítimas da violência. Ressalta-se que das ocorrências anotadas naquele levantamento sobre os dados coletados no ano de 2014 , só será destacado como objeto deste estudo o que diz respeito aos relacionados à violência física não letal praticada pelas mães; fornecidos pelo Sistema de Informação de Agravos de Notificação - SINAN - do Ministério da Saúde, que demandam atendimento pelo Sistema Único de Saúde - SUS, o que prejudica a exatidão fidedigna do número de episódios de violência. A violência praticada na vida privada jamais será conhecida em sua plenitude, uma vez que a violência física tem a cumplicidade do parceiro, camuflada pela autoridade da disciplina. "O que chega à luz pública, o que consegue furar o véu da vergonha, do estigma e do ocultamento, parece ser só a ponta do iceberg, uma mínima parcela das agressões, negligências e violências" (WAISELFISZ, 2012, p. 5) que permeiam a sociedade.

A violência parental se apresenta como um grave problema social, considerando as sequelas resultantes na vida das pessoas envolvidas. A violência intrafamiliar é comumente classificada em quatro espécies distintas: violência física, negligência ou omissão de cuidados, psicológica e sexual. O presente estudo tem como enfoque apenas a violência física, compreendida como todo o ato praticado capaz de trazer repercussão na vida das pessoas, com consequências externas e internas, causando dor física, produzida por um simples tapa até o espancamento (Maria Amélia AZEVEDO; Viviane Nogueira A. GUERRA, 2001).

Os pais, representando todos aqueles que estão na condição de pai ou mãe (integrantes da família ampliada), em sua maioria acabam praticando a 'pequena violência' como forma de educar; é a mania de bater (AZEVEDO; GUERRA, 2001): de forma consciente, por acreditar ser um meio necessário à disciplina e respeito; e de forma inconsciente, repetindo os meios utilizados pelos seus pais, configurando a assimilação constituída naturalmente no desenvolvimento humano. "O lar é de fato o lugar mais perigoso da sociedade moderna. Em termos estatísticos, uma pessoa de qualquer idade ou sexo está mais sujeita a ataques físicos dentro de casa do que à noite nas ruas" (GIDDENS, 2005, p. 167).

Segundo o Mapa Estatístico da Violência de 2015, prepondera o atendimento por violências praticadas por familiares nas residências das vítimas, sendo o sexo feminino mais atingido, ou seja, destes atendimentos, $82 \%$ das agressões a crianças do sexo feminino, de menos de um a 11 anos de idade, que demandaram atendimento pelo SUS, partiram dos pais - principalmente da mãe, que concentra $42,4 \%$ das agressões.

Independente da classe social, a prática da 'violência justificada' está inserida na rotina dos lares brasileiros, explicando a polêmica perenal sobre a elaboração, aprovação e sanção da lei da palmada. ${ }^{2}$ Fica manifesto o contrassenso da defesa teórica da não violência e a prática permissível da violência aplicada aos quais se ama, justificando tais atos como prova de amor, apesar da evidência do papel fundamental da criança como figura central da 'nova família' (FARIA, 2012). "Isso acontece porque na cultura brasileira bater nos filhos foi se constituindo em verdadeira marca da boa criação dos filhos e em verdadeira mania nacional" (AZEVEDO; GUERRA, 2001, p. 39).

O referido Mapa demonstra que a cada dia de 2014, 405 meninas/mulheres demandaram atendimento em uma unidade de saúde, por alguma violência sofrida, sendo que em todas as etapas da vida os atendimentos femininos preponderam. A incidência vai crescendo a partir do equilíbrio entre os atendimentos a crianças, quando $54,1 \%$ são meninas, e aumenta até a idade adulta, quando $71,3 \%$ dos atendimentos são de mulheres e só $28,6 \%$ de homens.

O número de atendimento por violência segundo a relação com o agressor, na faixa etária de menos de um ano de idade a 11 anos de idade, é de 6.849 crianças agredidas pela mãe, 4.758 pelo pai, 1.576 pelo padrasto e 81 pela madrasta.

A residência é o local privilegiado de ocorrência da violência não letal, para ambos os sexos, significativamente superior para o sexo feminino $(71,9 \%)$, em relação ao masculino $(50,4 \%)$. Em segundo lugar, a rua, local de ocorrência de 15,9\% das violências atendidas, no caso feminino, contra $30,6 \%$ dos atendimentos masculinos. Os índices representam em números: agressões na residência (13.561 meninas e 10.447 meninos vítimas); e sucessivamente, na escola (622 meninas, 738 meninos); bar (72 meninas e 68 meninos); rua (1.192 meninas e 1.594 meninos); outros (2.123 meninas e 2053 meninos).

'A concepção de que os pais têm o direito de usar a violência moderada como forma de disciplina e castigo dos filhos como forma da boa educação (AZEVEDO; GUERRA, 2001).

${ }^{2}$ Lei que altera a Lei $n^{\circ} 8.069$, de 13 de julho de 1990 (Estatuto da Criança e do Adolescente), e a Lei $n^{\circ} 9.394$, de 20 de dezembro de 1996 (Lei de Diretrizes e Bases da Educação Nacional), para estabelecer o direito da criança e do adolescente de serem educados e cuidados sem o uso de castigos físicos ou de tratamento cruel ou degradante. 
Com relação ao tipo de violência, se percebe que a violência física é, de longe, a mais frequente, presente em $48,7 \%$ dos atendimentos, com especial incidência nas etapas jovem e adulta da vida da mulher, quando chega a representar perto de $60 \%$ do total de atendimentos. Na faixa etária compreendida de menos de um ano de idade a 11 anos, independente do sexo, as ocorrências assim se apresentam: 6.020 crianças sofreram violência física, 4.242 psicológica, 402 tortura, 7.920 sexual e 7.732 foram vítimas de negligência e/ou abandono.

É bastante alarmante que os maiores níveis de encaminhamento correspondam aos atendimentos a crianças, com 58,5\% de encaminhamentos sobre o total de 20.707 atendimentos nessa faixa etária, de menos de um ano a 11 anos de idade e que em todas as idades, até os 59 anos, os atendimentos femininos superam os masculinos.

Os números retratam a triste realidade brasileira e evidenciam a falha do Estado e da sociedade em assegurar os direitos da criança preconizados pela Constituição da República Federativa do Brasil e pelo Estatuto da Criança e do Adolescente, entre outros instrumentos legais em favor da proteção de direitos.

Esses dados estatísticos são relevantes para o debate do amor materno natural, pois estampam de forma trágica que nem todas as mulheres estão de fato preparadas para a assunção do papel social de mãe. Badinter (1985) observa que

se é indiscutível que uma criança não pode sobreviver e desenvolver-se sem uma atenção e cuidados maternais, não é certo que todas as mães humanas sejam predestinadas a oferecerIhe esse amor de que ela necessita. Não parece existir nenhuma harmonia preestabelecida nem interação necessária entre as exigências da criança e as respostas da mãe. Nesse domínio, cada mulher é um caso particular. Algumas sabem compreender, outras menos, e outras ainda nada compreendem. E aí talvez esteja o mal metafísico, uma das causas essenciais da infelicidade humana. Mas será possível pensar em fugir desse mal negando sua existência? (p. 18).

A dependência do filho com a figura da mãe é intensa; desde a alimentação para sua sobrevivência aos primeiros passos para sua socialização, a qual vai definitivamente estruturar sua essência de ser humano relacional, pois "se o papel social e a ideologia mantêm uma certa identidade, é na família, local privilegiado de reprodução ideológica, que se desenvolve o aprendizado do primeiro papel social: o de filho" (REIS, 2012, p. 115).

A sociedade se reproduz dentro de nós em uma estrutura inconsciente, por meio da cópia do movimento, sobretudo dentro da família da qual surgimos. Esta estrutura que está internalizada inconscientemente se manifesta em algo que parece ser uma escolha sem motivo pessoal. Esse habitus (interiorização das estruturas sociais, tanto individuais quanto coletivas) fica impregnado de tal maneira no indivíduo, no seu sentido de mundo e na sua visão de mundo, que o elemento consciente não o identifica (Pierre BOURDIEU, 1989).

A estrutura é tão forte que mesmo os prejudicados por essas estruturas e concepções não percebem a indução sofrida e continuam a propagar o mesmo modelo pré-concebido internamente. A consciência sozinha não é suficiente, pois a transformação só pode ocorrer por meio da socialização (FARIA, 2012).

Não se trata apenas de ter consciência ou apontar a estrutura, mas principalmente de racionalizar que a transformação está nas entranhas do indivíduo formatado pelos conceitos, preconceitos, valores e estruturas replicadas de seus antecessores. O método empírico se faz indispensável para essa emancipação (BOURDIEU, 1989).

Os dados apresentados no Mapa da Violência revelam que a menina/mulher no Brasil, independente da idade, é alvo de agressões, tendo também na sua genitora o início de uma vida marcada pela dominação e opressão. Essa constatação sugere a repetição das violações ao feminino iniciadas no ambiente familiar.

Os resultados que apontam a mãe como a maior agressora podem apresentar um espectro de interpretações, tais como: consequência dela permanecer mais tempo com os filhos; por ser a responsável pela educação e disciplina; por centralizar os trabalhos domésticos; por repassar suas frustrações existenciais e dificuldades de afirmação pessoal; entre outras. Entretanto, o que não pode ser negligenciado e merece estudo aprofundado é o recorte de gênero na constatação de que a menina sofre mais agressão materna que o menino. Essa observação não é inovadora, pois já foi apontada no livro intitulado Mania de Bater, de 2001, onde as autoras, em análise aos números de uma pesquisa realizada com um grupo de crianças entre 7 e 12 anos de idade, concluem que "a mãe é de longe, a figura parental mais punitiva" (AZEVEDO; GUERRA, 2001, p. 192).

\section{A construção da maternagem}

Os números registrados podem parecer singelos frente ao grande número de mulheres que assume a maternagem com zelo, dedicação, abnegação e responsabilidade; porém, não se pode desconsiderar que os dados são significativos para a comprovação de que nem todas as mulheres representam a figura materna compulsoriamente caracterizada na sociedade hodierna. 
Nesse contexto, a análise é pertinente levando em conta que uma sondagem dos episódios pode retratar possibilidades de minorar os casos de violência praticada pelas mães contra suas crianças, também vítimas desta imposição social uniforme. Deve-se ressaltar que os números de violência praticada nos lares brasileiros são bem mais volumosos do que as estatísticas apresentadas, considerando que muitas práticas violentas não ultrapassam as paredes das casas, fomentadas pelo comportamento silente dos membros da família, inclusive das pessoas mais próximas.

Descontadas as situações da prática de atos violentos resultantes de patologias diagnosticadas nas mães agressoras, os demais comportamentos de fúria podem ser prevenidos, considerando que a maternagem é o resultado do exercício de apreender. Estar na condição de mãe é muito mais que um imperativo biológico ou determinismo social, é um estado de compreensão da participação na condução inicial da vida dos futuros cidadãos. O exercício da maternidade é fruto da conquista entre mãe e filho, somado à cooperação dos demais integrantes da família e da sociedade (Jane NELSEN, 2015).

Nesta acepção relacional, a maternagem (cuidados próprios de mãe) também configura uma condicionalidade surgida mediante as necessidades evolutivas sociais. "É na ordem original de realidade constituída pelas relações sociais que se deve compreender a família humana" (LACAN, 1997, p. 19).

Na atualidade, o estilo de vida assumido pelas mulheres não suporta mais o conformismo da aceitação de exclusividade dos encargos maternos. Ser mãe é tão natural quanto ser pai, porém a maternagem não é natural, ela é resultado de um trabalho relacional diário, favorecido pelo instinto materno, mas não dependente dele (FARIA, 2012).

Em muitas residências essa compreensão já existe, mesmo que inconscientemente, quando há partilha das atividades domésticas e coparticipação das responsabilidades básicas com os filhos, o que favorece a comunhão da maternagem com a maternidade. Todavia, em outras, especialmente nas famílias expostas a vulnerabilidades, esse proceder está bastante distante do ideário da família como entidade participativa, pois os papéis de pai e mãe continuam vinculados aos estereótipos predominantes do século XIX: pai provedor; mãe doméstica e educadora (SOUSA et al., 2007).

Observando-se a evolução comportamental da mãe, percebe-se que o interesse e a dedicação à criança se manifestam ou não, bem como as diferentes maneiras de expressar o amor. Ressalta-se que qualquer pessoa que não a mãe (o pai, avós, terceiros etc.) pode 'maternar' uma criança, pois não é só o amor maternal que leva a mulher a cumprir seus deveres maternais. "A moral, os valores sociais, ou religiosos, podem ser incitadores tão poderosos quanto o desejo da mãe" (BADINTER, 1985, p. 17).

Nestas condições se torna indispensável a reflexão sobre o papel da 'mãe' na sociedade contemporânea, buscando realçar a diferença entre maternidade e maternagem, num contexto que se impõe, de cunho ainda bastante teórico, do respeito aos melhores interesses da criança e ao princípio da afetividade.

A socialização presente nas relações entre mãe e filhos é uma preocupação emergente levando em conta as influências do capitalismo e da opressão sofridas pelas crianças no sentido de serem enquadradas no que é estipulado pela sociedade. "É preciso articular o pacto natural com o pacto social" (Leonardo BOFF, 2012, p. 112).

Enquanto não existir uma sensibilização à atuação materna violenta e dos sofrimentos suportados pela criança no interior de suas casas promovida pela ausência da maternagem, a prática da insignificância existencial do pequeno ser continuará sendo "tomado[a] como irrelevante e totalmente trivializado[a], por tratar-se 'apenas de crianças'. Em vinte anos essas crianças se tornarão adultos que farão seus filhos pagar a conta" (Alice MILLER, 1997, p. 75).

A capacitação para a maternagem pode apresentar inúmeros benefícios às novas gerações, potencializando uma inserção desses ensinamentos nas políticas públicas nacionais voltadas às Famílias, a exemplo da instrumentalização dos papéis femininos nos programas de assistência social vigentes (Silvana Aparecida MARIANO; Cássia Maria CARLOTO, 2009). Com apoio interdisciplinar, o tema pode ser abordado de maneira mais ampla e com possibilidades de atingir $\mathrm{o}$ agente destinatário, mormente por ser a maternagem (cuidados responsáveis) uma escolha.

\section{Cuidando de quem cuida}

Quando a violência física intrafamiliar é objeto de discussão, a "indignação em relação ao adulto que bate e a compaixão para com a criança indefesa obviamente acabam levandonos a logo cair na tentação de julgar e condenar o adulto como brutal e cruel" (MILLER, 2006, p. 121), desconsiderando qualquer análise mais aprofundada.

A mania de bater da mãe como forma de disciplinar o filho, independente da idade, evidencia a sua postura suscetível e vulnerável, e só vai decair sua aplicação quando conscientemente for apreendido pela genitora que a educação dos filhos não é de sua única 
responsabilidade e, principalmente, que não é pela prática de atos violentos que a criança irá ser disciplinada. "O cuidado como preocupação nos abre espaço para o cuidado precavido conosco mesmos, especialmente para com os nossos atos e atitudes e para o vasto campo das relações e da linguagem" (BOFF, 2012, p. 146).

O que se tem hoje é a repetição inconteste da prática da violência física como ato disciplinador, herança repassada de gerações a gerações e defendida como a melhor forma de adaptar o comportamento da criança aos desejos dos adultos. É o contumaz exercício da Síndrome do Pequeno Poder, que em efeito cascata atinge cada integrante da família, caminho de repasse das frustrações ao dominado mais próximo (AZEVEDO; GUERRA, 2000).

O digladiar proposto por Bourdieu (1989) está no fato de o agente se defender dele mesmo, como possibilidade de apresentar uma ruptura com a estrutura social a que está inserido, estrutura esta interiorizada e que leva à tomada de atitudes sedimentadas no caráter repetitivo social. Não havendo consciência disso, o agente é prisioneiro dessas estruturas e desse tipo de comportamento. A consciência desse mecanismo de incorporação de estruturas se aduz como a única forma de uma consciência crítica numa tentativa de libertação.

A forma possível de reverter ou de reduzir esse comportamento danoso à realidade da mulher e ao desenvolvimento da personalidade dos futuros adultos é dar uma atenção diferenciada à mãe dessas crianças, partilhando ensinamentos via interdisciplinaridade, objetivando a mudança de postura de mulher enquanto mãe. É promover a desmistificação da figura imaculada de Mãe; apresentando a mulher, que com todas as problemáticas de um ser humano, está na condição de maternidade.

Reconhecer a inaptidão para controlar os próprios instintos agressivos configura o início de uma terapia de pacificação e transformação emancipatória. Propiciar a compreensão de que a agressão é fruto do lado mais primitivo da natureza, e que estimular a capacidade de integrar razão à emoção, ligando o neocórtex ao sistema límbico (que comanda as emoções), se apresenta como a primeira medida a ser adotada com a finalidade de atenuar o estresse maternal (Ligia Moreiras SENA; Andreia C. K. MORTENSEN, 2014).

A potencialidade transformativa dessa figura materna pode ser promovida por meio de grupos de apoio, redes sociais que tratam do tema, amigos, familiares, ajuda profissional e da inclusão do cuidado materno nas políticas públicas existentes nos programas de atendimento das famílias. "O cuidado das pessoas, das sociedades e da natureza será a atitude mais adequada e imprescindível para a nova fase da história da humanidade e da própria Terra" (BOFF, 2012, p. 103).

É fato que já existe uma significativa preocupação do Estado e de algumas instituições civis no sentido de amparar a mãe gestante e a criança nos primeiros meses de vida, quer seja pelo acompanhamento médico, quer pelo auxílio material (enxoval) do bebê. Porém, há uma invisibilidade do papel social da mãe na continuidade dos cuidados com $\circ$ filho, e consigo mesma, depois do advento do nascimento. Há um vazio de informações necessárias ao controle das próprias emoções de maneira positiva, da habilidade de identificar, usar e entender o exercício da inteligência emocional. "Cuidar e ser cuidado são duas demandas fundamentais de nossa existência pessoal e social” (BOFF, 2012, p. 29).

Orientações primárias como a prática de atividades relaxantes, terapia familiar, o desenvolvimento da consciência emocional, a evitabilidade dos ruídos de comunicação entre mãe e filho (o jeito como se diz), a reciclagem das expressões imperativas, o cultivo do bom humor, entre outras, potencializam a capacitação da maternagem e abrandariam expressivamente os episódios de práticas violentas contra as pequenas crianças (SENA; MORTENSEN, 2014).

A tratativa da matéria nos meios de comunicação (mídia falada, escrita e televisiva), nos bancos escolares e nas redes de proteção possibilita debates importantes sobre o papel da mãe na família contemporânea, suas conquistas e suas necessidades. A replicação de uma nova postura, oportunizada pelo caráter mimético, a médio e longo prazo, favorecerá uma ruptura do habitus de bater como forma de disciplina e extravasamento de conflitos internos da mãe. Para mudança do comportamento fica patente, em alguns casos, a necessidade de "orientação, apoio e até tratamento psicológico para questionar e reformular sua atitude ante a infância e a educação, sua e de seus filhos" (FERRARI; VECINA, 2002, p. 130).

Qualquer mulher organicamente saudável pode se tornar biologicamente uma mãe; mas nem toda mulher tem como inata a maternagem. Para ser uma 'boa mãe' dependerá das condições de escolha e preparação para esse atuar, cujos requisitos asseguram a conquista saudável de cumprir com a nobre missão de criar e educar seus filhos em parceria com os demais integrantes da família.

"Mais que uma técnica, o cuidado é uma arte, um paradigma novo de relacionamento para com a natureza, para com a Terra e para com os seres humanos" (BOFF, 2012, p. 21). Nesta situação, é indubitável que, para a mulher manter sua saúde social estável, dependerá de um prognóstico e terapia adequadas para a prevenção e evitamento da violência como forma de resolução dos conflitos experimentados na maternagem. 


\section{Considerações finais}

Muitas mulheres brasileiras ainda continuam moldadas para servir ao marido e aos filhos, independentemente de sua classe social, grau de escolaridade, raça ou credo. Prosseguem oprimidas pela sua condição de submissão, antes restritas à obediência e ao poder econômico, hoje pela mantença da união familiar, felicidade dos filhos, questão econômica, carência afetiva e/ou medo da violência enrustida no pseudoafeto do companheiro.

É fato, porém, que as mudanças estão cada vez mais frequentes com as novas gerações, aspirações e influências culturais diversas, propiciadas pelo mundo virtualmente conectado. Os costumes são alterados de modo constante e gradativo, oportunizando a transformação no molde preestabelecido do papel social da mulher brasileira, da sua importância como partícipe da constituição familiar e não como responsável majoritária pelo sucesso do microssistema (família). Contudo, as conquistas profissionais e de poder não inibiram a injunção da responsabilidade materna pela criação dos filhos e dos cuidados mantenedores da administração doméstica, sobrecarregando a vivência do Ser feminino.

O estudo trouxe uma reflexão sobre os fatores de risco ou de proteção para o uso da força física empregada pelas mães aos filhos ainda na infância, e destacou a prevenção como uma potencialidade viável na modificação das estruturas geracionais; considerando que "não se trata de culpar os pais individualmente, que afinal também são vítimas desse sistema, mas de perceber uma estrutura social oculta, que, como nenhuma outra, determina nossa vida" (MILLER, 2006, p. 224).

Assim, considerando que a maternagem representa um processo construído e reconstruído gradativamente, segundo a vivência experimentada por cada integrante da família (criação humana mutável), a discussão coletiva sobre as formas alternativas de convívio com suas crianças é fator preponderante e emergente no mundo moderno, tanto no interesse sociológico quanto terapêutico.

Com esta preocupação, acredita-se na compreensão capacitadora, sem violência, da postura materna como partícipe da criação dos filhos, devendo contar, para tanto, com a intervenção do Estado, da sociedade e de profissionais habilitados para o trato da saúde social da mulher do século XXI; proporcionando-lhe o reconhecimento e orientação necessários para o desempenho do papel social na condição de mãe, e não na obrigação da maternidade por imperativo biológico e social.

Sem um despertar, as pessoas estão inclinadas a não se abrir ao novo conhecimento e a continuar procurando apoio nas antigas regras, inviabilizando a emancipação progressiva do indivíduo. Compreendendo que toda violência é social, histórica e, portanto, capaz de ser controlada e erradicada se houver vontade política, a habitualidade da violência empreendida pela mãe contra a criança pode ser bastante minorada. "A lenta e gradativa transformação das coisas miúdas do cotidiano pode levar às grandes transformações históricas e sociais" (AZEVEDO, 2011 , p. 76).

A orientação direcionada ao fenômeno do proceder maternal estruturada no princípio do cuidado, da tolerância, do cultivo e controle da inteligência emocional da mulher-mãe representará uma conquista importante no cenário feminino e na convivência intrafamiliar. "A prevenção perpassa os diversos serviços e políticas públicas com diferentes alcances e níveis específicos" (FERRARI; VECINA, 2002, p. 232).

Nesse sentido, a prevenção pode se tornar um contrapoder ${ }^{3}$ e favorecer o diálogo construtivo, pois ela impõe uma contraviolência simbólica ao poder simbólico, reforçando a função primordial da família: a socialização primária.

\section{Referências}

ABOIM, Sofia. "Conjugalidades no masculino: renegociando poderes e identidades no quotidiano". In: WALL, Karin; ABOIM, Sofia; CUNHA, Vanessa. A vida familiar no masculino: negociando velhas e novas masculinidades. Lisboa: Estudos 6, Editorial do Ministério da Educação, 2010. Disponível em http://cm-cuba.pt/ficheiros/Planolgualdade/docs/ A_vida_familiar_no_masculino_CITE.pdf. Acesso em 03/07/2018.

ARIÈS, Philippe. História Social da Criança e da Família. Tradução de Dora Flaksman. 2.ed. Rio de Janeiro: LTC, 1981.

AZEVEDO, Maria Amélia; GUERRA, Viviane Nogueira A. Crianças vitimizadas: a síndrome do pequeno poder. São Paulo: Iglu, 2000.

${ }^{3}$ Contrapoder com o significado de ação, atividade, operação ou movimento que se opõe a um poder previamente estabelecido. 
AZEVEDO, Maria Amélia; GUERRA, Viviane Nogueira A. Mania de bater: a punição corporal doméstica de crianças e adolescentes no Brasil. São Paulo: Iglu, 2001.

AZEVEDO, Maria Amélia; GUERRA, Viviane Nogueira A. Infância e violência doméstica: fronteiras do conhecimento. São Paulo: Cortez, 2011.

BADINTER, Elisabeth. Um Amor Conquistado: o Mito do Amor Materno. Tradução de W. Dutra. Rio de Janeiro: Nova Fronteira, 1985.

BOFF, Leonardo. O cuidado necessário: na vida, na saúde, na educação, na ecologia, na ética e na espiritualidade. Petrópolis: Vozes, 2012.

BOURDIEU, Pierre. O Poder Simbólico. Tradução de F. Torrez. Rio de Janeiro: Bertrand Brasil, 1989.

DONZELOT, Jacques. A Polícia das famílias. Tradução de M. T. da Costa Albuquerque; revisão técnica de J. A. Guilhon Albuquerque. Rio de Janeiro: Graal, 1980.

FARIA, Adalberto. As Novas Famílias do Século XXI. Lisboa: Coisas de Ler, 2012.

FERRARI, Dalka C. A.; VECINA, Tereza C. C. O Fim do Silêncio na Violência Familiar: Teoria e Prática. São Paulo: Ágora, 2002.

FRIEDAN, Betty. Mística Feminina. Tradução de Áurea B. Weissenberg. Petrópolis: Vozes, 1971.

GIDDENS, Anthony. Sociologia. Tradução de S. R. Netz. Porto Alegre: Artmed, 2005.

GOFFMAN, Erving. Estigma - notas sobre a manipulação da identidade deteriorada. Tradução de M. Lambert. Rio de Janeiro: Zahar Editores, 2004.

GUERRA, Viviane Nogueira de Azevedo. Violência de Pais contra Filhos: a tragédia revisitada. São Paulo: Cortez, 2001.

KRISTEVA, Julia. Sol Negro: depressão e melancolia. Tradução de Carlota Gomes. Rio de Janeiro: Rocco, 1989.

LACAN, Jacques. Os Complexos Familiares na Formação do Indivíduo. Tradução de M. A. C. Jorge e P. M. Silveira Junior. Rio de Janeiro: Jorge Zahar, 1997.

LOPES, Manuela Nunes; DELLAZZANA-ZANON, Letícia Lovato; BOECKEL, Mariana Gonçalves. "A multiplicidade de papéis da mulher contemporânea e a maternidade tardia". Temas em Psicologia, v. 22, n. 4, p. 917-928, 2014. Disponível em https://dx.doi.org/10.9788/TP2014.4-18. Acesso em 15/07/2018.

MARIANO, Silvana Aparecida; CARLOTO, Cássia Maria. "Gênero e Combate à Pobreza: Programa Bolsa Família”. Revista Estudos Feministas, v. 17, n. 3, p. 901-908, 2009.

MINAYO, Maria Cecília de Souza. "Violência: um problema para a saúde dos brasileiros". In: SOUZA, Edinilsa Ramos de; MINAYO, Maria Cecília Souza (org.). Impacto da violência na saúde dos brasileiros. Brasília: Ministério da Saúde, 2005. p. 09-33.

MILLER, Alice. O drama da criança bem dotada: como os pais podem formar (e deformar) a vida emocional dos filhos. 2.ed. São Paulo: Summus, 1997.

MILLER, Alice. Não perceberás: variações sobre o tema do paraíso. Tradução de I. A. Lohbauer. São Paulo: Martins Fontes, 2006.

NELSEN, Jane. Disciplina positiva. 3.ed. Tradução de B. P. Rodrigues e S. Schreier Susyn. Barueri: Manole, 2015.

OLIVEIRA, Olga Maria Boschi Aguiar de. Mulheres e Trabalho. Desigualdades e Discriminações em Razão de Gênero. Rio de Janeiro: Lumen Juris, 2016.

REIS, José Roberto Tozoni. "Família, emoção e ideologia". In: LANE, Silvia T. Mauer; CODO, Wanderley (org.). Psicologia Social: o homem em movimento. São Paulo: Brasiliense, 2012. p. 99-124.

SENA, Ligia Moreiras; MORTENSEN, Andreia C. K. Educar sem violência: criando filhos sem palmadas. São Paulo: Papirus 7 Mares, 2014.

SOUSA, Liliana; HESPANHA, Pedro; RODRIGUES, Sofia; GRILO, Patrícia. Famílias Pobres: Desafios à Intervenção Social. Lisboa: Climepsi Editores, 2007. 
TOMAZ, Renata. "Feminismo, maternidade e mídia: relações historicamente estreitas em revisão". Galáxia, São Paulo, n. 29, p. 155-166, jun. 2015. Disponível em www.scielo.br/pdf/gal/n29/19822553-gal-29-0155.pdf. Acesso em 10/07/2018.

WAISELFISZ, Julio Jacobo. Mapa da Violência 2015: Homicídio de Mulheres no Brasil. Disponível em http://www.mapadaviolencia.org.br/pdf. Acesso em 11/1 1/2016.

WAISELFISZ, Julio Jacobo. Mapa da Violência 2012: Crianças e Adolescentes. Disponível em http:/ /www.mapadaviolencia.org.br/pdf. Acesso em 13/10/2016.

Maria Cristina Baluta (cristinabaluta@hotmail.com) é doutoranda do Programa de PósGraduação em Ciências Sociais Aplicadas da Universidade Estadual de Ponta Grossa - UEPG. Mestre em Ciência Jurídica pela Universidade do Vale do Itajaí (UNIVALI). Docente lotada no Departamento de Direito Processual do Curso de Direito da Universidade Estadual de Ponta Grossa UEPG.

Dircéia Moreira (dirceiam@gmail.com) é doutora em Direito das Relações Sociais pela PUC-SP (2004). Docente da Pós-Graduação stricto sensu em Ciências Sociais Aplicadas da UEPG e professora Adjunta lotada no Departamento de Direito Processual do Curso de Direito da Universidade Estadual de Ponta Grossa - UEPG. Advogada.

COMO CITAR ESSE ARTIGO DE ACORDO COM AS NORMAS DA REVISTA

BALUTA, Maria Cristina; MOREIRA, Dircéia. "A injunção social da maternagem e a violência". Revista Estudos Feministas, Florianópolis, v. 27, n. 2, e48990, 2019.

\section{CONTRIBUIÇÃO DE AUTORIA}

Maria Cristina Baluta - concepção, elaboração do manuscrito, redação

Dircéia Moreira - concepção, elaboração do manuscrito, redação

\section{FINANCIAMENTO}

Não se aplica

\section{CONSENTIMENTO DE USO DE IMAGEM}

Não se aplica

APROVAÇÃO DE COMITÊ DE ÉTICA EM PESQUISA

Não se aplica

\section{CONFLITO DE INTERESSES}

Não se aplica

\section{LICENÇA DE USO}

Este artigo está licenciado sob a Licença Creative Commons CC-BY Internacional. Com essa licença você pode compartilhar, adaptar, criar para qualquer fim, desde que atribua a autoria da obra.

\section{HISTÓRICO}

Recebido em 13/02/2017

Reapresentado em 18/07/2018

Aprovado em 08/10/2018 